\section{Vanishing websites are the weakest link}

Sir - Referencing websites for supplementary data and online applications is increasingly popular and acceptable in today's scientific publishing. Yet my recent experience of testing the validity of web links referenced in papers published in 1998 supports the view that many websites are valid for only a short time.

I used PubMed to search for papers using the string "http", and found about 300 citations. Of the 265 web links that appeared in abstracts, only $150(57 \%)$ are still valid; 97 (36\%) are no longer available and $18(7 \%)$ redirected me to other URLs. Although these statistics are biased towards biomedical research and might not reflect other disciplines, they are discouraging.

The root of the problem is the formidable challenge of maintaining a website indefinitely. Many websites are stored on local servers, managed by system and network administrators who are not necessarily aware of the need to maintain links cited in publications in unaltered form. Other problems abound: for example, individual researchers might lose data in computer breakdowns, and the ownership of Internet domain names is often out of their control.

Authors must therefore take great care when citing web links. They must ensure that any website they create to supply additional information will be maintained indefinitely before referencing it in their publications. If authors need to reference websites belonging to other organizations or individuals, they should try to use only those that have been cited in other publications, as these sites are usually better maintained. Authors should redirect outdated web links to current URLs. Publishers should encourage authors to deposit their supplementary information in databases that are maintained carefully by the publishers. Many publishers now use the Digital Object Identifier (DOI) system to guarantee linkage, but this does not solve the problem of links to supplementary information in various academic or other informal websites. Further, DOI is relatively expensive for academics to set up on their own websites.

Given the convenience of the Internet, more and more information will be stored digitally as time goes on and URL references will become increasingly common. The

\title{
Recognizing risks and potential promise of germline engineering
}

\section{The consequences of mitochondrial DNA manipulation are unknown, but sufferers of some diseases might benefit.}

Sir-Your informative News Feature on germline engineering, "Biology's last taboo" (Nature 413, 12-15; 2001), suggests that the presence of donated mitochondria in a human embryo created with donor cytoplasm does not constitute germline engineering. Specifically, the feature states: "Mixing mitochondria does not risk damaging important chromosomal genes, nor could it endow children with eugenic traits." Gregory Stock of the University of California, Los Angeles, is quoted as saying that applying the term 'germline engineering' to this situation is "playing games with words".

Unfortunately, we know that devastating human diseases - heritable through the female line - can be caused by mutations occurring in the handful of genes carried on the mitochondrial genome and required for oxidative phosphorylation. It is not true to suggest that harm to the germline cannot come from mitochondrial manipulation. It's less clear whether mitochondrial DNA manipulation could result in inheritance of positive traits, but one might speculate that the rate or efficiency of oxidative phosphorylation could affect highly energetic tissues, say of muscle and nervous system, with unknown consequences.

You mention the work of Jacques Cohen and colleagues, using donor cytoplasm and mitochondria to 'rejuvenate' the eggs of women with fertility problems. This is not inconsequential to women of child-bearing age who have been diagnosed with a mitochondrial DNA disease. A process such as this 'rejuvenation' may hold the possibility of allowing these women to bear children who do not carry the mutant mitochondrial DNA in their genomes. Thus it represents exactly the same promise of germline engineering discussed in relation to chromosomal DNA defects. This is not to support or condone the work conducted by Cohen, but merely to point out its significance.

Sharon E. Hesterlee

Muscular Dystrophy Association, 3300 E. Sunrise

Drive, Tucson, Arizona 85718, USA lifetime of those references will determine how often we face a missing link. Joseph Cheung

Department of Genetics and Genomic Biology, The Hospital for Sick Children, 555 University Avenue, Toronto, Ontario M5G 1X8, Canada

Nature's policy on supplementary information has always been to host such material on its own website so that its integrity is maintained indefinitely. See www.nature.com/nature/submit/gta/ index.html\#4.10 — Editor, Nature.

\section{Give and take the lead}

Sir - Your News report "Stanford gift scaled back over federal stem-cell policy" (Nature 413, 5; 2001) notes that Jim Clark, the founder of Netscape, has retracted his $\$ 60$-million pledge to support a biomedical research centre at Stanford University, in retaliation for President Bush's decision to limit support for stem-cell research. Clark has wasted an opportunity to make good on the boldness inherent in the tradition of strategic private philanthropy.

Private philanthropy, at its best and most influential, is about doing what the government will not do because it is too controversial, risky or unpopular. The Rockefeller Foundation supported population research when timid governments would not. The Parkinson's Disease Foundation nurtured fetal cell transplantation research. The Aaron Diamond Foundation led the way supporting AIDS research.

The federal government must answer to the diverse interests, beliefs and desires of the public. Clark is spending his own money and answers only to himself. Government institutions can have their hands tied by bureaucracy and political expediency. Clark wisely pledged his support to a private institution free from such restraints. The bold response to President Bush's plan shouldn't be withdrawing money — it should be spending it!

So much of the current stem-cell debate is focused on pie-in-the-sky promises or nit-picking technicalities. Let's use private money to fund the research, let's get the data out there, and let's use the scientific findings to guide policy debates. Holding research hostage to a financial game of chicken accomplishes nothing. Clark could have made good on his pledge, upped the ante and challenged others to follow. Taking a stand and mobilizing the vast private wealth of this country - that would be a brave and daring manoeuvre. Susan M. Fitzpatrick

James S. McDonnell Foundation, 1034 South Brentwood Boulevard, Suite 1850, St Louis, Missouri 63110, USA 